WellBeing International

WBI Studies Repository

$5-1964$

\title{
Estimates of Heritability of Beef Cattle Performance Traits by Regression of Offspring on Sire
}

\author{
C. J. Brown \\ University of Arkansas, Fayetteville \\ Maximo Gacula \\ University of Arkansas, Fayetteville
}

Follow this and additional works at: https://www.wellbeingintlstudiesrepository.org/geneti

Part of the Animal Studies Commons, Other Animal Sciences Commons, and the Other Genetics and Genomics Commons

\section{Recommended Citation}

Brown, C. J., \& Gacula, M. (1964). Estimates of Heritability of Beef Cattle Performance Traits by Regression of Offspring on Sire 1, 2. Journal of Animal Science, 23(2), 321-324. https://doi.org/10.2527/ jas1964.232321x

This material is brought to you for free and open access by WellBeing International. It has been accepted for inclusion by an authorized administrator of the WBI Studies Repository. For more information, please contact wbisr-info@wellbeingintl.org.

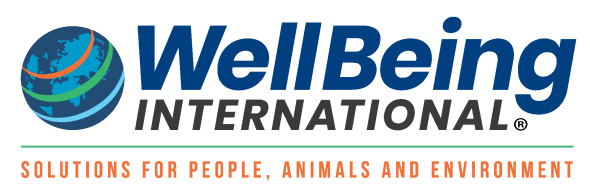




\title{
ESTIMATES OF HERITABILITY OF BEEF CATTLE PERFORMANCE TRAITS BY REGRESSION OF OFFSPRING ON SIRE ${ }^{1,2}$
}

\author{
C. J. Brown and Maximo Gacula \\ University of Arkansas, Fayetteville
}

$\mathbf{E}$ STIMATES of heritability of economic traits in beef cattle vary according to methods of estimation, sources of environmental effects and genetic variability of the population being studied. In populations where parents are selected and offspring unselected, the regression of offspring on parent leads to a reliable estimate of heritability (Lush, 1948). In beef cattle populations, because of difficulties encountered in obtaining suitable data, few heritability estimates have been derived from the regression of progeny performance on sire preformance. Using this procedure heritability estimates of eight performance traits of beef bulls fed on postweaning gain tests were obtained and are reported in this study.

\section{Materials and Methods}

Data studied were the performance records of sires that were raised, performance tested and selected for use in Arkansas Agricultural Experiment Station herds and the performance test records of their male progeny. There were records of 20 sires, with 201 progeny, tested between 1951 and 1962. The breed and number of progeny tested in each sire progeny group are given in table 1 .

During the performance test calves were individually fed a ration of one-third prairie hay and two-thirds grain mixture for 154 days. Grain intake was limited according to the weight of daily hay intake. Performance tests were started either in mid-May or mid-November. Gains were calculated from initial and final weights on test. Feed consumption was the total feed eaten during the test period and, because of the daily adjustment of grain to hay intake, was one-third hay and twothirds grain. Performance test procedures were described in detail by Brown and Gifford (1962). Type scores were taken near the end of the feeding period using the scorecard described by Brown et al. (1953).

\footnotetext{
1 Published with approval of the Director of the Arkansas Agricultural Experiment Station.

2 A publication of Southern Regional Beef Cattle Breeding Project, S-10.
}

At the end of the test a production index was calculated for each bull, which gave equal emphasis to 120-day weight $\left(\mathrm{X}_{1}\right)$, average daily gain on test $\left(\mathrm{X}_{2}\right)$, feed conversion on test $\left(\mathrm{X}_{3}\right)$, and type score $\left(\mathrm{X}_{4}\right)$. The formula for this index was:

Production Index $=75+\frac{10}{4}$

$\left[\frac{\left(\mathrm{X}_{1}-\overline{\mathrm{X}_{1}}\right)}{\mathrm{s}_{1}}+\frac{\left(\mathrm{X}_{2}-\overline{\mathrm{X}}_{2}\right)}{\mathrm{s}_{2}}-\frac{\left(\mathrm{X}_{3}-\overline{\mathrm{X}_{3}}\right)}{\mathrm{s}_{3}}+\frac{\left(\mathrm{X}_{4}-\overline{\mathrm{X}_{1}}\right)}{\mathrm{s}_{4}}\right]$

where $X_{i}$ is an observation, $\vec{X}_{i}$ is the mean and $s_{i}$ is the standard deviation of the trait considered.

In a preliminary analysis it was determined that there were differences between tests which must be taken into account, since a sire and his offspring were evaluated in different tests. The differences between tests have been shown to account for 14 to $26 \%$ of the variance in these traits (Brown and Gifford, 1962). In order to standardize the data for test differences, the record of each bull for each trait was expressed as a deviation from the mean of the group with which he was tested. In table 2 is presented the range of the observations of sires and sons for the eight performance traits studied. These values are expressed as deviations from the average of test contemporaries. There is a slightly greater range for all traits in the record of sires than there is in the range of the averages of their sons.

The regression coefficients of offspring records on sires' records were calculated using the deviations of each trait. Heritability estimates and standard errors based on regression coefficients were calculated by three different methods. Method 1 was the regression of the mean of the sons' records on sires' records. Method 2 was the regression of sons' records on sires' records with the sires' records repeated for each son. Method 3 was the weighted regression technique described by Kempthorne and Tandon (1953) and elaborated on by Bohren et al. (1961). 
TABLE 1. BREED OF SIRE SHOWING NUMBER OF SONS TESTED

\begin{tabular}{lcc}
\hline & & No. of \\
Sire no. & Breed $^{a}$ & $\begin{array}{c}\text { Nogeny } \\
\text { progen }\end{array}$ \\
\hline U257 & A & 2 \\
U336 & A & 3 \\
U414 & A & 4 \\
U462 & A & 23 \\
U615 & A & 18 \\
U195 & A & 2 \\
L2 & A & 4 \\
L9 & A & 18 \\
L397 & A & 10 \\
L413 & A & 17 \\
L414 & A & 16 \\
U221 & H & 14 \\
U267 & H & 17 \\
U268 & H & 5 \\
U411 & H & 25 \\
U533 & H & 5 \\
R820 & H & 3 \\
G858 & H & 6 \\
U115 & S & 7 \\
U138 & S & 2 \\
\hline & & \\
\hline & &
\end{tabular}

a $\mathrm{A}=$ Aberdeen-Angus, $\mathrm{H}=$ Hereford, $\mathrm{S}=$ Shorthorn.

\section{Results and Discussion}

Heritability estimates of the eight performance traits are shown in table 3. These estimates are on a within-sex basis since only bull calves were fed on test. They are on a within-test basis because of the procedure used to standardize for test differences. Since only British breeds with similar performance were included, the analysis was not made on a within-breed basis and any breed differences would tend to inflate the heritability estimates. According to Dickerson (A.S.A.P.,
1960) the coefficient from the sire offspring regression arises from $50 \%$ of the additive effects, $25 \%$ of the covariance between genetic deviations in the transmitted and the direct maternal effects, $25 \%$ of the two-loci interactions and a small amount of the higher order interactions. Except for 120-day weight and initial test weight, the traits studied should be uncomplicated by maternal effects.

The estimates of heritability obtained by the three methods are presented in table 3. The relative efficiencies of these three methods of estimation were compared by McKean and Bohren (1961) who indicated that methods 2 and 3 are preferred over method 1. Method 3 is preferred over method 2 provided a reliable estimate of the correlation between the deviations of two offspring of the same parent from the predicted breeding value of the parent can be estimated and this correlation is high. These workers point out in certain circumstances a poor choice of method can lead to a serious loss in efficiency in estimation of the regression coefficient and thus heritability in the narrow sense. It is of interest to note in this respect that the heritability of the eight traits estimated in this study do not differ greatly when obtained by the three methods. The greatest difference among the three estimates was in final weight for which the estimates were $0.19,0.40$ and 0.37 for methods 1,2 and 3 , respectively. In the following discussion reference is made only to estimates obtained by method 3 .

The estimate of heritability of 120-day weight was $0.19 \pm 0.19$. No other published

TABLE 2. THE RANGE OF SIRE'S RECORD AND AVERAGE SONS' RECORDS EXPRESSED AS A DEVIATION FROM THE MEAN OF THEIR CONTEMPORARY TEST GROUP

\begin{tabular}{|c|c|c|c|c|}
\hline \multirow[b]{2}{*}{ Trait } & \multicolumn{2}{|c|}{ Sire } & \multicolumn{2}{|c|}{ Sons' average } \\
\hline & $\begin{array}{l}\text { Largest deviation } \\
\text { below average }\end{array}$ & $\begin{array}{l}\text { Largest deviation } \\
\text { above average }\end{array}$ & $\begin{array}{l}\text { Largest deviation } \\
\text { below average }\end{array}$ & $\begin{array}{l}\text { Largest deviation } \\
\text { above average }\end{array}$ \\
\hline $\begin{array}{l}\text { 120-day weight, } \\
\text { lb. }\end{array}$ & -41 & 79 & -49 & 23 \\
\hline $\begin{array}{l}\text { Initial test weight, } \\
\text { Ib. }\end{array}$ & -187 & 173 & -65 & 36 \\
\hline $\begin{array}{l}\text { Test av. daily gain, } \\
\text { lb./day }\end{array}$ & -.4 & 0.5 & -.4 & 0.3 \\
\hline $\begin{array}{l}\text { Total feed consumption, } \\
\text { lb. }\end{array}$ & -677 & 676 & -328 & 221 \\
\hline $\begin{array}{l}\text { Feed conversion, } \\
\text { lb. feed/lb. gain }\end{array}$ & -3.0 & 4.0 & -1.0 & 2.0 \\
\hline $\begin{array}{l}\text { Type score, } \\
\text { scorecard points }\end{array}$ & -9 & 14 & -7 & 4 \\
\hline $\begin{array}{l}\text { Final test weight, } \\
\mathrm{lb} \text {. }\end{array}$ & -162 & 214 & -52 & 41 \\
\hline $\begin{array}{l}\text { Production index, } \\
\text { index points }\end{array}$ & -10 & 12 & -8 & 9 \\
\hline
\end{tabular}


TABLE 3. HERITABILITY ESTIMATES AND STANDARD ERRORS BASED ON REGRESSION COEFFICIENTS ESTIMATED BY THREE DIFFERENT METHODS

\begin{tabular}{|c|c|c|c|}
\hline \multirow[b]{2}{*}{ Performance trait } & \multicolumn{3}{|c|}{ Method } \\
\hline & $1^{a}$ & $2^{b}$ & $3^{\circ}$ \\
\hline 120-day weight & $0.18 \pm 0.25$ & $0.28 \pm 0.18$ & $0.19 \pm 0.19$ \\
\hline Initial test weight & $0.15 \pm 0.18$ & $0.27 \pm 0.09 *$ & $0.27 \pm 0.13^{*}$ \\
\hline Average daily gain & $0.80 \pm 0.18^{* *}$ & $0.96 \pm 0.13^{* *}$ & $0.93 \pm 0.18^{* *}$ \\
\hline Feed consumption & $0.43 \pm 0.21$ & $0.43 \pm 0.10^{*}$ & $0.43 \pm 0.18^{* *}$ \\
\hline Feed conversion ${ }^{a}$ & $0.35 \pm 0.27$ & $0.42 \pm 0.13 * *$ & $0.41 \pm 0.25$ \\
\hline Final test weight & $0.19 \pm 0.14$ & $0.40 \pm 0.10^{* *}$ & $0.37 \pm 0.14^{* *}$ \\
\hline Type score & $0.11 \pm 0.22$ & $0.21 \pm 0.12$ & $0.15 \pm 0.15$ \\
\hline Production index & $0.77 \pm 0.29^{*}$ & $0.80 \pm 0.18^{* *}$ & $0.79 \pm 0.18^{* *}$ \\
\hline
\end{tabular}

a. Regression of progeny average on sire's record.

b Sire's record repeated for each progeny record.

e Kempthorne-Tandon weighted regression technique.

a Adjusted for differences in initial weight.

* Regression coefficient significant $(\mathbf{P}<.05)$.

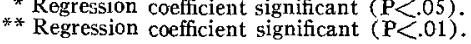

estimate of this trait in beef cattle was available. Differences in 120-day weight are expected to be largely the result of differences in maternal environment provided by the dam. Weight taken at this age expresses maternal environment more accurately than weights taken later in the preweaning period, because some calves are able to eat enough to compensate for low milk production of their dams. Since differences in maternal environment are not genetic insofar as the calf is concerned, a heritability estimate of this trait would be expected to be low.

The estimate of heritability of initial test weight was comparable to estimates of heritability of weaning weight in many studies since the bulls were started on test about 2 weeks after weaning. The average age of calves when started on test was 235 days. The heritability estimate of initial test weight was $0.27 \pm 0.13$. This trait is influenced by maternal environment in the same manner as 120-day weight, but to a lesser extent. This estimate is in agreement with recent estimates from more extensive data of which these are a part and the studies of Koch and Clark (1955), Lasley et al. (1961) and Blackwell et al. (1962).

The heritability estimate of gain on performance test was $0.93 \pm 0.18$. This was the most highly heritable trait included in this study. Heritability of this magnitude indicates the considerable genetic improvement which ought to be possible through phenotypic selection for rate of gain. The estimate obtained in this study is higher than an average heritability value for gain in feedlot of 0.53 estimated by sire-offspring regression method that may be calculated from the reports of Knapp and Clark (1950), Knapp and
Nordskog (1946), Carter and Kincaid (1959), and Chambers et al. (1960).

The estimate of heritability of total feed consumption was $0.43 \pm 0.18$. This is smaller than the value of 0.76 obtained in a paternal half-sib analysis of the data from which these sire progeny groups were taken (Brown and Gifford, 1962). It is in close agreement, however, with the estimate of 0.38 by England et al. (1961), the estimate of $0.45 \pm 0.46$ and $0.38 \pm 0.36$ reported by Swiger (1961) and the combined estimate of $0.64 \pm 0.12$ reported by Koch et al. (1963).

The heritability estimate of feed conversion in this study was $0.41 \pm 0.25$ which is less than the value of 0.80 obtained by Brown and Gifford (1962). This difference in estimates from the same body of data could be the result of sampling or of different methods of estimation. Carter and Kincaid (1959) reported 0.22 for heritability of feed conversion calculated from offspring-sire regression. Other estimates obtained by paternal half-sib procedures were 0.22 and 0.32 by Shelby et al. $(1955,1960), 0.27$ and 0.36 by Lickley et al. (1959) and 0.36 by Koch et al. (1963).

The estimate of $0.15 \pm 0.15$ for heritability of type score was low. This value is much smaller than the 0.58 reported by Brown and Gifford (1962) in the paternal half-sib analysis. The reason for this wide difference is not clear. Heritability estimates for type score and grade reviewed in the literature ranged from 0.16 to 0.63 with an average of 0.41 .

The heritability estimate of final test weight was $0.37 \pm 0.14$. This is below the estimate of 0.85 reported by Brown and Gifford (1962) and others reviewed. Estimates of heritability of final feedlot weight based on 
offspring-sire regression were 0.92 by Knapp and Clark (1950) and 0.54 by Chambers et al. (1960). An average of recent estimates obtained by paternal half-sib methods by Shelby et al. (1960, 1963), Swiger (1961) and Blackwell et al. (1962) was 0.62.

The heritability estimate obtained for the production index was $0.79 \pm 0.18$. This index was arbitrarily chosen to give equal emphasis to 120-day weight, test daily gain, feed conversion and type score. The heritability estimate was high. Perhaps the averaging of traits in calculating the index cancelled some of the errors in evaluation. Such an index might have value for expressing general genetic potential for beef production of a bull when the herd situation in which he will be used is unknown.

\section{Summary}

Data used in this study were taken from performance test records of Hereford, Aberdeen-Angus and Shorthorn sires and their progeny that were raised and performance tested at the Arkansas Agricultural Experiment Station during the years 1951 through 1962. Heritability estimates based on regression of offspring on sire were obtained from 201 male progeny belonging to 20 sire groups. The estimates obtained were $0.19 \pm 0.19$ for 120-day weight, $0.27 \pm 0.13$ for initial test weight, $0.93 \pm 0.18$ for test daily gain, $0.43 \pm$ 0.18 for feed consumption, $0.41 \pm 0.25$ for feed conversion, $0.15 \pm 0.15$ for type score, $0.37 \pm$. 0.14 for final test weight, and $0.79 \pm 0.18$ for production index.

\section{Literature Cited}

A.S.A.P. 1960. Techniques and Procedures in Animal Production Research. American Society of Animal Production.

Blackwell, R. L., J. H. Knox, C. E. Shelby and R. T. Clark, 1962. Genetic analysis of economic characteristics of young Hereford cattle. J. Animal Sci. 21:101.

Bohren, B. B., H. E. McKean ad Yukio Yamada. 1961. Relative efficiencies of heritability estimates based on regression of offspring on parent. Biometrics 17:481.

Brown, C. J. and Warren Gifford. 1962. Estimates of heritability and genetic correlations among certain traits of performance-tested beef bulls. Ark. Agr. Exp. Sta. Bul. 653.

Brown, C. J., W. Gifford and M. L. Ray. 1953. A subjective method for evaluating conformation of beef cattle-permanency and accuracy of conformation scores. Ark. Agr. Exp. Sta. Bul. 540.

Carter, R. C. and C. M. Kincaid. 1959. Estimates of genetic and phenotypic parameters in beef cattle. II. Heritability estimates from parent-offspring and half-sib resemblances. J. Animal Sci. 18:323.

Chambers, D., J. B. Armstrong and D. F. Stephens. 1960. Progeny testing beef bulls for growth. Okla. Agr. Exp. Sta. Misc. Publ, MP-64.

England, N., J. Brinks, R. Bogart and R. T. Clark. 1961. Evidence for genetic influence on appetite in beef cattle. J. Animal Sci. 20:905 (Abstr.).

Kempthorne, O. and O. B. Tandon. 1953. The estimation of heritability by the regression of offspring on parent. Biometrics 9:90.

Knapp, B. and R. T. Clark. 1950. Revised estimates of heritability of economic characteristics of beef cattle. J. Animal Sci. 9:582.

Knapp, Bradford, Jr. and A. W. Nordskog. 1946. Heritability of growth and efficiency in beef cattle. J. Animal Sci. 5:62.

Koch, R. M. and R. T. Clark. 1955. Genetic and environmental relationships among economic characters in beef cattle. II. Correlations between offspring and dam and offspring and sire. J. Animal Sci. 14:786.

Koch, Robert M., L. A. Swiger, Doyle Chambers and K. E. Gregory. 1963. Efficiency of feed use in beef cattle. J. Animal Sci. 22:486.

Lasley, J. F., B. N. Day and J. E. Comfort. 1961. Some genetic aspects of gestation length and birth and weaning weights in Hereford cattle. J. Animal Sci. 20:737.

Lickley, C. R., H. H. Stonaker, T. M. Sutherland and K. H. Riddle. 1959. Relationship between mature size, daily gain, and efficiency of feed utilization in beef cattle. J. Animal Sci. 18:957 (Abstr.).

Lush, J. L. 1948. The Genetics of Populations. Ames, Iowa (Mimeo.).

McKean, H. E. and B. B. Bohren, 1961. Numerical aspects of regression of offspring on parent. Biometrics 17:626.

Shelby, C. E., R. T. Clark, J. R. Quesenberry and R. R. Woodward. 1960 . Heritability of some economic characteristics in records of performance bulls. J. Animal Sci. 19:450.

Shelby, C. E., R. T. Clark and R. R. Woodward. 1955. The heritability of some economic characteristics of beef cattle. J. Animal Sci. 14:372.

Shelby, C. E., W. R. Harvey, R. T. Clark, J. R. Quesenberry and R. R. Woodward. 1963. Estimates of phenotypic and genetic parameters in ten years of Miles City R.O.P. steer data. J. Animal Sci. $22: 346$.

Swiger, L. A. 1961. Genetic and environmental influences on gain of beef cattle during various periods of life. J. Animal Sci. 20:183. 